\title{
CONTROL OF HAZARDS IN THE LUMINOUS DIAL PAINTING INDUSTRY
}

\author{
BY
}

J. C. JONES and M. J. DAY

From the Department of Physics, Middlesex Hospital Medical School, London

The paint which is applied to the dials of instruments so that the figures and pointers shall be visible in the dark consists of a mixture of zinc sulphide with a very small proportion of radium sulphate. A proportion of seventy millionths of a gram (70 micrograms) of radium element to $1 \mathrm{~g}$. of zinc sulphide is commonly used. Zinc sulphide alone will glow in the dark after it has been exposed to light, but the luminosity disappears after a few hours. To ensure a continuous luminosity the admixture of radium is necessary. The rays from the radium which are in themselves invisible cause the zinc sulphide to give off a greenish light, a phenomenon which is known as fluorescence.

The mixture of zinc sulphide and radium sulphate is made up into a paste, usually with gum arabic and applied to the figures and pointers of the dials with small applicators made of wood, metal, or plastic. The dials are left overnight in a dark room in order that any luminosity due to the previous exposure to light of the zinc sulphide should have disappeared. They are then tested against standard dials which are illuminated from behind. The operatives who apply the paint are known as luminizers or radium dial painters, and the workrooms as luminizing rooms.

During the 1914-18 war the demand for aeroplane instrument dials which were self-luminous produced a considerable increase in the number of persons employed in the industry. In the years 1918-30 several fatalities occurred in the U.S.A. among persons who had been so employed, which were thought to be due to the absorption of radium. Most of these operatives suffered from aplastic anaemia and many of them showed bone changes which culminated in osteogenic sarcoma. An account of the early work which was done in this field and of the attempts to trace the cause of these fatalities is given by Martland (1931). The clinical symptoms did not generally appear for some years after the persons had left the work. In some cases they were delayed for as many as ten years. Since that time a considerable amount of work has been done on the subject and an account of this will be found in papers by Evans (1943) and others. A comprehensive list of references is given in a review by Read (1939).

\section{Radioactivity}

Before discussing the hazards involved in this work and the physical measurements involved in their control, it is necessary to describe the general properties of radium and allied substances. Radioactive substances, of which the element radium is the best known member, spontaneously emit radiations. These radiations arise from the disintegration of the atoms of the elements and are of three types. The alpha-rays are streams of helium atoms, each with a positive electric charge shot out from the nucleus with high velocity. The beta-rays consist of electrons, ejected from the atoms with very high speeds. The gamma-rays, which accompany the production of alpha- and beta-rays, are electromagnetic radiations, similar in nature to $\mathrm{x}$-rays.

All three types of ray produce ionization in any medium through which they pass; that is, they are capable of removing electrons from the atoms of the medium and thus of transforming them into positively charged particles or ions. It is probably this property which produces deleterious effects on living tissue cells. By the production of these positively charged atoms inside the cells the chemical equilibrium is disturbed; this inhibits mitosis and, if great enough, may cause the death of the cell. This property is used to measure the intensity of the radiations. Air is normally a non-conductor of electricity, but if any of these radiations pass through it they cause it to become a conductor. If two metal plates separated by a layer of air or other gas are connected to an electrical supply no current will pass between them; but if a radioactive substance be placed nearby, the air will become a conductor and current will pass. By measuring the magnitude of this electric current the intensity of the rays from the radioactive material can be determined. From this the amount of radioactive material present can be estimated. In practice the current passing between the outer walls of a cylindrical chamber and a central metallic rod is measured (fig. 1). The radioactive material may be outside the chamber, in which case the radiations must pass through the walls; or, if it is a gas, may be within the chamber. Such a vessel is called an ionization chamber. 


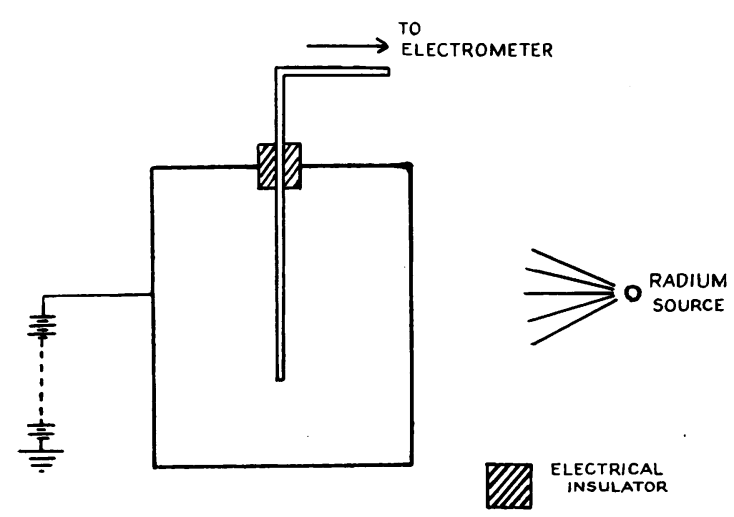

FIG. 1.-Ionization chamber.

The alpha-rays have a very low penetrating power, being stopped by a few centimetres of air and about a tenth of a millimetre of human tissue. Being comparatively massive (they are about 8000 times as heavy as an electron) they travel in straight lines and produce intense ionization along their tracks. The beta-rays are more penetrating, being able to penetrate several metres of air. The ionization along their tracks is correspondingly less dense. The gamma-rays have a much higher penetrating power and produce diffuse ionization throughout the medium.

These rays are produced by a series of disintegrations of the nuclei of the radioactive atoms. The radium atom disintegrates, emitting an alpha particle and becomes itself a radon atom. Radon is a heavy and chemically inert gas. It is itself radioactive and disintegrates, producing an alpha particle and becoming an element known as radium A. A whole series of disintegrations takes place and the final product is lead:

$$
\begin{gathered}
\text { radium } \rightarrow \text { radon } \rightarrow \text { radium } \mathrm{A} \rightarrow \text { radium } \mathrm{B} \rightarrow \\
\quad \rightarrow \text { radium } \mathrm{C} \rightarrow---\rightarrow \text { lead }
\end{gathered}
$$

The rate at which the atoms are disintegrating is proportional to the total number of atoms present. Thus, if the radon which is produced by a specimen of radium be collected and its radioactivity studied separately, the intensity of the rays emitted decreases with time. In 3.85 days it would fall to half its original value. The radiation from a radium tube which has been sealed for some time consists of all three radiations corresponding to the different stages in the disintegration series. Thus the gammarays, which are emitted from a radium needle used in therapy, are produced by the breakdown of the radium $\mathrm{C}$ atom.

If radium is deposited in the body, part of the radon produced remains in the tissues, and the rest is expired through the lungs. Thus the gammarays, produced from radium in the body, would be less than those from a sealed radium tube containing the same amount of radium, for some of the radium $C$, produced from the exhaled radon, is deposited outside the body. The percentage of the total radon produced which is expired, is called the emanating power of the radium deposit. This factor is important in the estimation of the quantity of radium in the body. The elements radium $A$, radium $B$ and radium $C$ are solids and are deposited when the radon atoms disintegrate. This solid deposit is usually called the 'active deposit' of radium. It is itself radioactive and capable of causing injury to the tissues if deposited in them.

The units we have used to express quantities of radium in the body and concentrations of radon gas in air are the microgram and the eman. One microgram is one millionth of a gram. The eman is defined as a concentration of one ten-thousandmillionth part of a curie per litre of air, the latter unit being the quantity of radon which produces the same intensity of gamma radiation as one gram of radium.

\section{Hazards}

The various hazards involved in the manufacture and use of radioactive substances in industry may be classified according to the radiations responsible for them.

(a) Alpha-rays.-Owing to their low penetrating power these rays can only cause damage to the tissues by the immediate contact of unscreened radioactive material. In practice this may be brought about by the absorption of radium into the body through the mouth, as dust through the lungs, by the deposition of radioactive material on the skin, and also by the breathing of air containing dangerous quantities of radon gas which is given off from the radium. The condition produced by the absorption of radioactive material into the body is known as radium poisoning.

(b) Beta-rays.-Although stopped by a few millimetres of most solid material these rays can penetrate several metres of air producing intense ionization in the region of the source. Obviously it is the hands which are subject to the greatest exposure from this source.

(c) Gamma-rays.-The harmful effects produced by gamma-rays are well known from experience in hospital radium and $\mathrm{x}$-ray departments. The tolerance dose rate of one roentgen per week is generally accepted. The roentgen is the physical unit of quantity of $\mathrm{x}$ or gamma radiation defined by the International Congress of 1928 on the basis of the ionization produced by these rays. It gives a measure of the total energy absorbed per unit volume of tissue from the $\mathrm{x}$ - or gamma-rays. In comparison with other workers handling radioactive materials in this industry the risk of damage from the gamma radiation is small. In hospitals a radium officer may safely handle several hundreds of milligrams of radium for a short time. The quantity of radium on the factory bench is seldom more than 0.4 milligrams for each operator. On the other hand, in hospitals, the radium is sealed up in containers through which the alpha- and betarays cannot penetrate. The risk of absorption of radium into the body by hospital workers is negligible. 


\section{Methods of Protection}

Safety measures necessary in industry fall into two groups. Firstly, there are precautions designed to reduce unavoidable exposure to a minimum and to improve the general conditions of work; these are laid down by the British Radium and X-ray Protection Committee (1943), and the Ministry of Labour and National Service (1942, 1943). The correct emphasis on the different aspects of protection can only be assured by quantitative measurement of the radon and radium dust in the atmosphere and on the beta- and gamma-ray intensities.

Secondly, direct examination of the operatives themselves for indications of over-exposure is necessary; this entails on the medical side routine blood examination, inspection of the hands for signs of local effects and attention to the general health of the workers, and on the physical side the wearing of beta- and gamma-ray sensitive photographic films and tests for radium in the body.

\section{Radium Poisoning}

The symptoms of radium poisoning are so severe (Browning, 1944), and the quantities of radioactive material required to produce them are so small, that it must be regarded as the most important risk run by those working with ' naked' radium. Early work on the internal administration of radium salts for therapeutic purposes showed that not all the radium ingested is retained. At first elimination is rapid, and at the end of a few weeks, if the radium has been taken orally, only about 10 per cent. remains in the body. (About 90 per cent. of the radium eliminated appears in the faeces and 10 per cent. in the urine). The elimination rate decreases until after a year, the radium remaining may be considered as virtually fixed in the body and is to be found mainly in the skeleton with rather smaller concentrations in the lung, liver, spleen, and heart (Reid, 1939). The percentage retained is about 1-2 per cent. if the radium has been taken by mouth and 2-10 per cent. if it has been inhaled by dust.

It has been established that it is possible for 1 microgram of radium remaining in the body to cause death (Evans, 1943) though cases have been reported of persons apparently unaffected by quantities up to 10 micrograms.

From the physical point of view a microgram of radium produces ionization effects of the same order of magnitude as are produced by an x-ray dose rate of one roentgen per week, the accepted tolerance value. The effects of the alpha-rays are much more localized. Thus a very high dose rate is maintained for a very short time over very small volumes and the affected cells probably have less chance of recovery. Gray and Reid (1942) found that it required a physical dose of gamma-rays about nine times the alpha-ray dose to kill a broad bean root tip.

It is clear that in order to avoid danger to health the radium content of the body should be considerably below 1 microgram. Curtiss (1942) and Evans
(1943) both suggest a maximum allowable amount of $0 \cdot 1$ micrograms. The British X-ray and Radium Protection Committee suggest that there should be no more radium in the body than will produce a concentration of $0 \cdot 1$ emans in the expired air. The relation between these recommendations is seen when it is realized that there are two methods for the detection of such small quantities of radium in the body: (a) direct measurement of the gammaray intensity produced by the radioactive substances in the body and (b) the measurement of radon appearing in the expired air which is proportional to the radium content of the body if the emanating power remains constant. It is clear that the first method measures the quantity of disintegration products emanating in the body and the second those given off. For a complete estimate both measurements should be made. Thus if 50 per cent. of the radon produced escaped in the expired air, a concentration of 0.1 eman in the breath would indicate a deposit of 1.6 micrograms. Variations from 90 per cent. to 10 per cent. have been found in the emanating power in individual cases. It appears to decrease with the time the radium has been in the body. It has not been found easy to measure by the gamma-ray method quantities of radium less than 0.2 micrograms. This quantity of radium would produce a concentration of radon in the expired air of 0.01 emans if the emanating power was 40 per cent. It is therefore suggested that the total quantity of radium in the body should be less than $\mathbf{0 . 2}$ micrograms and that the concentration of radon in the breath should not exceed 0.01 emans. (The figures refer to a time when the radium has become fixed in the body.) Considerably higher quantities are permissible if measurements can be made within a few days after the ingestion of the radium. If it is suspected that a sudden large intake of radium has taken place measurements on the expired air should be made as soon as possible; but if any ingestion takes place it is probably fairly continuous, so where a deposit is detected it is safer to assume that the radium has become fixed unless very frequent routine tests prove otherwise.

Prevention of the intake of radium through the mouth is achieved by insistence on strict adherence to working rules laid down by the Ministry of Labour and National Service. Where radium dust concentrations are appreciable, suitable face masks are useful, but it is more important to keep the radium dust to as low a value as possible. Calculation can be made of the concentration of radium dust in the air required to produce an accumulation of 0.1 micrograms of radium in the body at the end of the year. Assuming a breathing rate of 10 litres per minute, a 40-hour working week, and a 10 per cent. retention of radium (all of which err if anything on the high side), the value obtained is 0.8 micro-micrograms * of radium per litre. The radium dust concentration should therefore be kept well below 1 micro-microgram per litre.

* 1 micro-microgram $=1$ million millionth of a gram. 


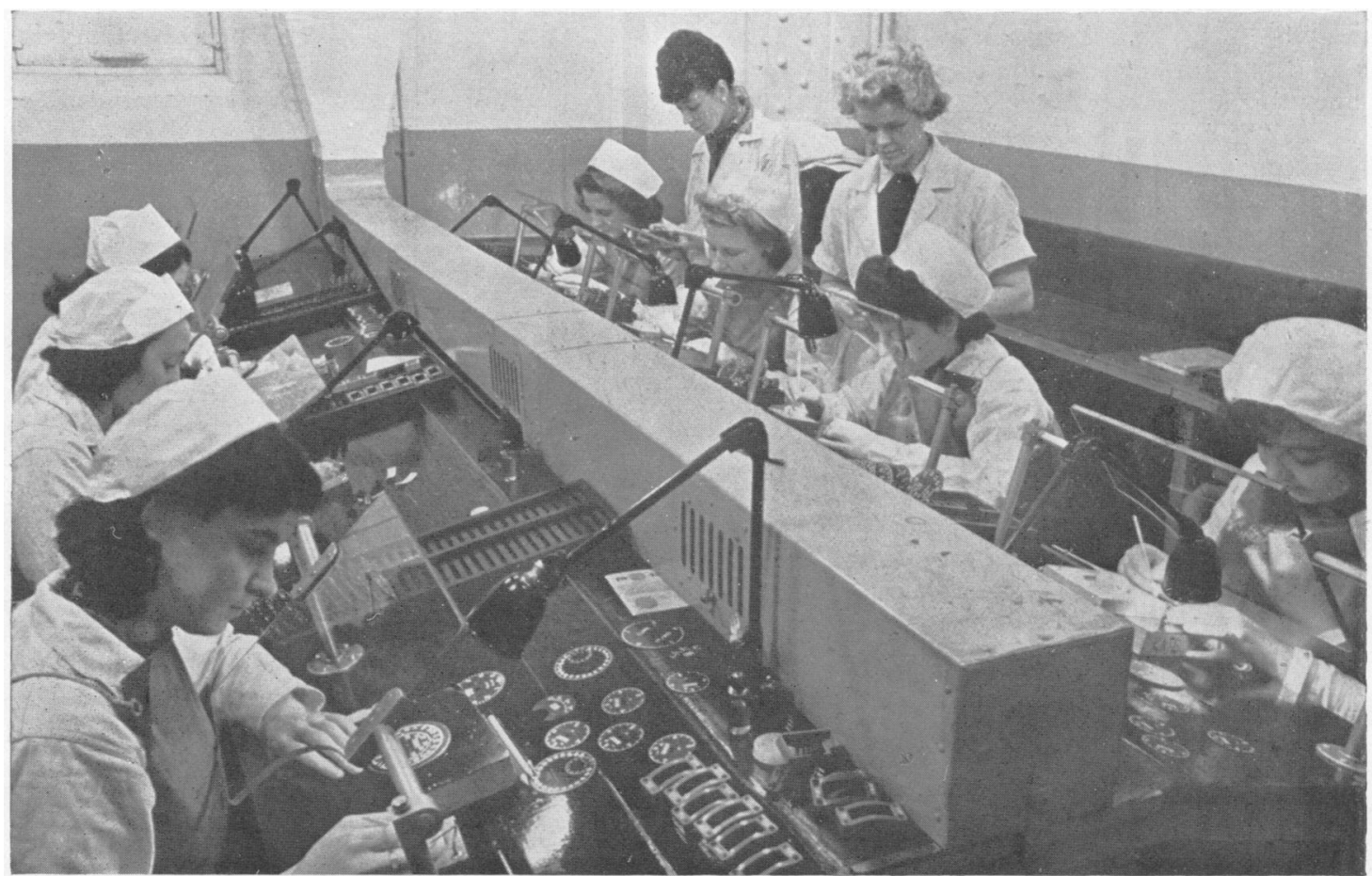

FIG. 2.-Girls luminizing. Note protective aprons, lead glass screens in front of operatives, and local exhaust ventilation system.

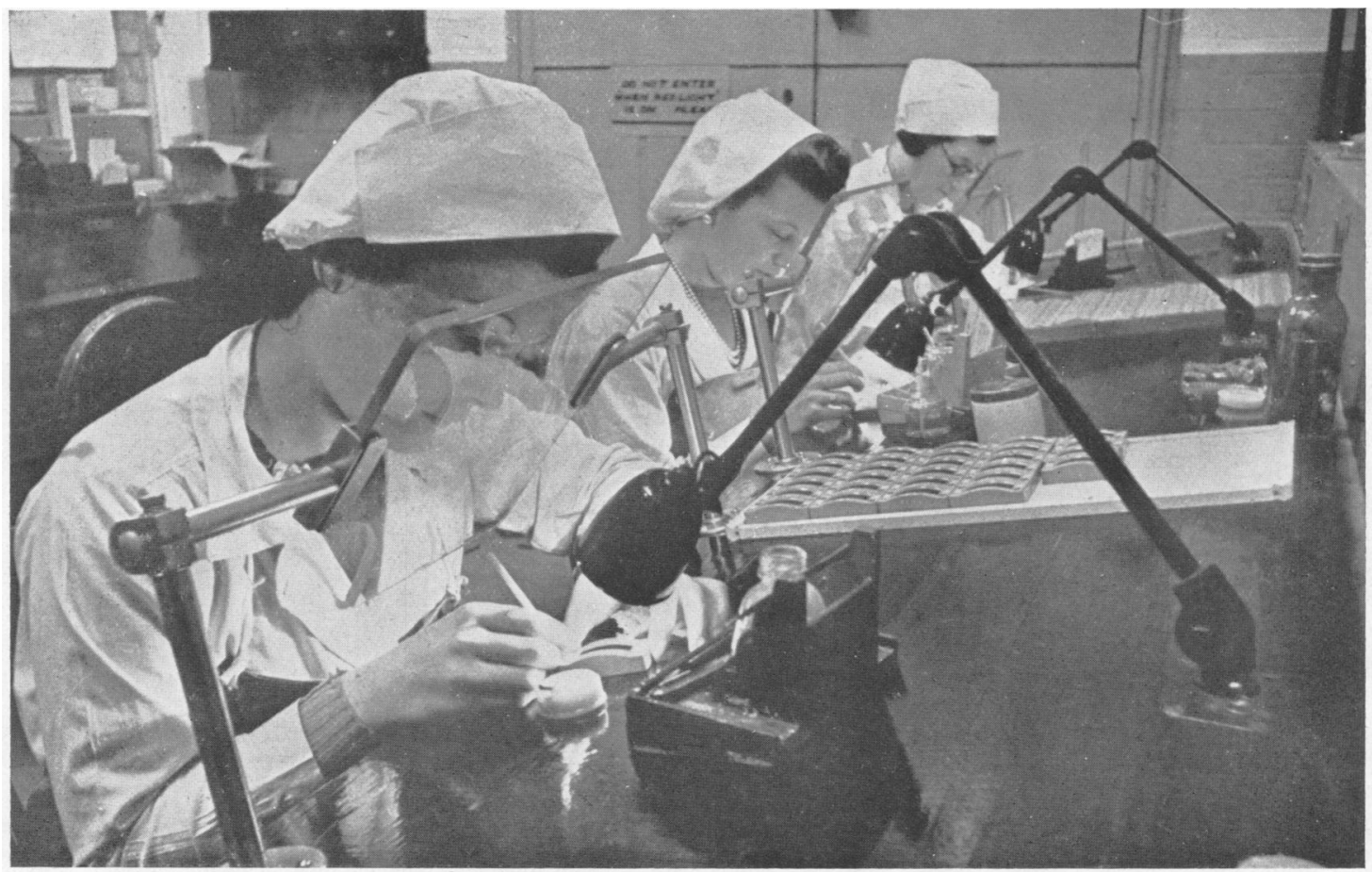

Fig. 3.-Showing protection afforded by lead glass screens in front of operatives.

(By courtesy of Smith Accessories, Lt.l., Cricklew'ood.) 


\section{Radon in the Atmosphere}

A clear distinction should be made between the radon which arises from the radium in the body and is present in the expired air even when the operator is expiring normal air, and the radon which arises from the radium on the benches of the workroom and which is breathed in by the operator. It is established that the breathing of radon can produce harmful effects, but direct experimental evidence on the actual concentration required to do this is meagre. The incidence of lung carcinoma is high among workers in the Joachimsthal mines (Martland, 1931) where the radon concentration seems to average about 50 emans and occasionally rises to 200 emans. But it is by no means certain that this is the cause of the trouble, for the presence of arsenic dust in the air may have some effect. Various tolerance concentrations have been suggested for the radon in atmospheric air breathed by operatives. Mottram and Reid (1939) found that for mice a concentration of 1000 emans does not produce any appreciable effect on the growth rate for 161 days, though 5000 emans is fatal within a few weeks. Exact comparison between mice and men is uncertain, but they suggest that as it is not difficult to keep the concentration of radon below 10 emans this figure should be aimed at. The tolerance concentrations put forward by the British $\mathrm{X}$-ray and Radium Protection Committee and by Evans (1943) are respectively 1 and $0 \cdot 1$ emans.

In practice the main justification for such a low tolerance as 1 eman lies in the comparative ease with which concentrations may be kept below this value by exhaust ventilation (Hemon and Evans, 1943; Williams and Evans, 1942). We doubt however whether as low a value as $0 \cdot 1$ eman can be justified as a restricting working condition.

\section{Measurement of Radium in the Body}

It is important that direct tests should be made for the presence of radium in the body in order that operatives may be put off work and possibly treated with the object of increasing the rate of elimination of radium from the body if ingestion has indeed taken place. The two available methods of measuring the quantity of radium in the body are: $(a)$ direct gamma-ray measurement, and $(b)$ measurement of the concentration of radon in the expired air after the operator has been breathing normal air for some time in order to ensure all the radon in the expired air does actually come from radium in the body. One microgram of radium in the body gives from 0.01 to 0.2 emans in the expired air according to the emanating power of the radium in the body.

\section{Expired Air Tests}

In spite of the variation in the emanating power, which leads to uncertainty in the interpretation of results, this method has many advantages; it is the only one which can readily be applied on a large scale. Collection of breath samples is comparatively easy whereas the gamma-ray test involves the presence of the operative at the laboratory. Ac- cordingly, this method of detecting ingested radium was first developed and we have found it possible during the later part of the work to detect a concentration of 0.02 emans corresponding to $0.2-2.0$ micrograms of radium.

Samples of expired air were collected in litre aspirators by displacement of water. The operator was asked to attempt to empty his or her lungs completely; although this does not give the concentration of radon in the normal expired air, we thought that it would be likely to produce a higher concentration than normal breathing, thereby rendering the detection of small quantities somewhat easier. Samples were collected on Monday mornings before the operators started work, after breathing normal air since Saturday. Some spuriously positive results were later traced to contamination of the atmosphere in which the samples were taken so that later samples were taken in the open air as far as possible. Control samples of atmospheric air were always taken.

\section{Gamma-ray Tests}

When testing patients, they were instructed to lie on a couch as closely as possible on the arc of the circle of a metre radius centred on the ionization chamber. Patients bathed and washed their hair after their last visit to work and, if they could not

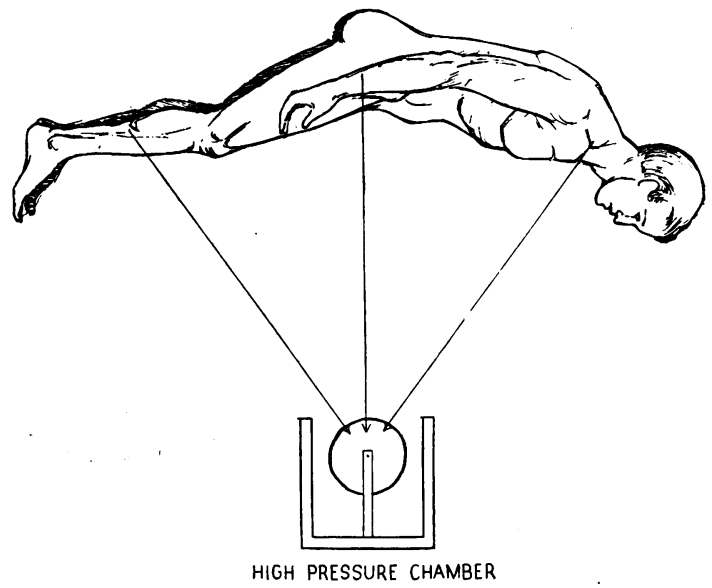

FIG. 4.-Gamma-rays from deposits of radium in the body cause current to flow in the ionization chamber.

wear clothes which had not been near the luminizing room, they changed into hospital clothing. Quantities of the order of a microgram have been found in clothing which had only been worn at work a few times and the ordinary working clothes must often contain many times this amount, since even the under-clothes have been said to glow in the dark. During the test luminous wrist watches had to be removed to a safe distance.

After measurements on the total activity with the patient one metre from the chamber, further measurements were made in different positions with the chamber close to the patient, as a test for small localized quantities of radium. One patient's 
hair was found to be slightly contaminated in this way, the activity disappearing after thorough washing.

\section{Results of Tests for Radium in the Body}

The expired air from 120 operatives at 32 factories has been tested. Of these 11 showed positive results with concentrations ranging from 0.02 to 0.09 emans. Owing to the comparative insensibility of our apparatus any positive result was deemed to be significant and it was recommended that these persons be removed from work. There seemed to be some correlation between the period of employment and the positive results, all those concerned having been working with radium for more than 18 months and 2 of them for more than two years. Several of these workers were tested again, along with a batch of others, by the gamma-ray and breath methods about a year later and the results are shown in Table 1. In the one apparently positive case

TABLE 1

GAMMA RAY TESTS FOR RADIUM IN THE BODY

\begin{tabular}{|c|c|c|c|c|c|}
\hline \multirow{2}{*}{ No. } & \multirow{2}{*}{ Employment } & \multirow{2}{*}{$\begin{array}{l}\text { Period of } \\
\text { employ- } \\
\text { ment }\end{array}$} & \multirow{2}{*}{$\begin{array}{c}\text { Gamma-ray } \\
\text { activity } \\
\text { (micro- } \\
\text { grams) }\end{array}$} & \multicolumn{2}{|c|}{$\begin{array}{l}\text { Radon content } \\
\text { of expired } \\
\text { air (emans) }\end{array}$} \\
\hline & & & & $\begin{array}{c}\text { At } \\
\text { time of } \\
\text { gamma- } \\
\text { ray } \\
\text { test }\end{array}$ & $\begin{array}{c}\text { Pre- } \\
\text { vious } \\
\text { test }\end{array}$ \\
\hline $\begin{array}{r}1 \\
2 \\
3 \\
4 \\
5 \\
6 \\
7 \\
8 \\
9 \\
10\end{array}$ & $\begin{array}{l}\text { Luminizer } \\
\text { Charge hand } \\
\begin{array}{l}\text { Luminizer } \\
\text { Luminizer }\end{array} \\
\begin{array}{l}\text { Luminizer } \\
\text { Luminizer }\end{array} \\
\begin{array}{l}\text { Luminizer } \\
\text { Chemist }\end{array} \\
\begin{array}{l}\text { Chemist } \\
\text { Radium techni- } \\
\text { cian .. }\end{array}\end{array}$ & 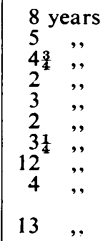 & 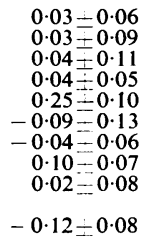 & $\begin{array}{c}<0.02 \\
<0.02 \\
<0.02 \\
0.05 \\
0.1 \\
<0.02 \\
<0.02 \\
0.06 \\
0.04 \\
<0.02\end{array}$ & $\begin{array}{c}<\overline{0.03} \\
0.2 \\
0.04 \\
0.05 \\
0.03 \\
0.6 \\
0.05 \\
- \\
<0.05\end{array}$ \\
\hline
\end{tabular}

The errors given are the standard deviations from the mean of several physical determinations. There is a probability of 19 to that the actual values do not vary from the mean by more than twice the above limits. Negative values indicate that the instrument indicated less ionization with the patient near to it.

measurements with the high-pressure chamber close to the body seemed to indicate that the radium was concentrated in the region of the head, probably in the hair. We were unable to carry out further tests to confirm this and the breath test was inconclusive, the control sample showing that the atmosphere in which it was done was contaminated with radon. The discrepancy between the results shown in Table 1 and the earlier breath tests may possibly be explained by the contamination with luminous paint of the clothing of those tested, or by the fact that previous to the test they had been in an atmosphere outside the luminizing room where concentrations of radon were sometimes as high as inside.

\section{Measurement of Radon and Radium Dust Concentrations in the Workrooms}

Atmospheric air samples were collected from workrooms usually during the middle of the morning. Three types of workrooms were concerned in these tests. Firstly, the luminizing room where the actual dials are painted with the radium and zinc sulphide mixture. The number of the operatives in the room varied from one to thirty, but the rooms were usually large and exhaust ventilation was in use in nearly every case. Of the 37 rooms tested, 7 showed a concentration of less than $0 \cdot 2$ emans, 25 had between 0.2 and 1.0 emans and only 5 showed a higher concentration than this, the highest being 6 emans. It is obvious, therefore, that for these rooms there is no difficulty in reducing the concentration to less than that recommended by the British X-ray and Radium Protection Committee.

The second type was the dark room, small and often unventilated, where the luminized dials are placed over night before being tested for luminosity. Three rooms showed concentrations less than $0 \cdot 2,11$ came between $0 \cdot 2$ and $1 \cdot 0$ emans and 11 from 1 to 6 emans. It should be borne in mind that the operative is only in the room for a few hours a day, but even so the concentrations seem high.

The third type was the radium laboratory and other places where large quantities of radium were used or stored. There the concentrations were much higher, only 1 being below $0 \cdot 2$ emans, 5 between 0.2 and 1.0 eman and no less than 7 greater than 1.0 emans, the maximum being 8.0 emans.

The concentrations of radium dust ranged from 2 micro-micrograms per litre to 10 micro-micrograms per litre. Measurements were only carried out in one factory which specialized in the production of the luminous compound, but it is very probable that the dust concentrations in luminizing rooms would be considerably smaller. The face masks used in the factory where tests were made consisted of a wad of cotton wool between layers of surgical gauze, tied over the mouth and nose by tapes (see figs. 5 and 6). They showed an efficiency of about 60 per cent. when stretched over a glass funnel at an air flow rate slower than the normal breathing rate. The efficiency of the mask must be appreciably lower in practice, since air probably leaks between the face and the mask.

In luminizing operations, the beta and gamma radiations are probably the least likely to produce serious harm.

\section{Note on the Accidental Dispersal of Radium}

During the course of this work we were concerned with two cases which showed in a remarkable manner the persistence of spilt and scattered radium. In the first of these $50 \mathrm{mg}$. of radium, in solution as bromide, were thrown from a window over a lawn. An area of about seven square yards was excavated to a depth of two feet and fresh soil put in. About three months later we examined the site with a neon tube radium finder and estimated that there were still approximately $5 \mathrm{mg}$. present.

In the second case, radium paint containing about $50 \mathrm{mg}$. of radium was scattered in a fire caused by enemy action. It was originally kept in a second- 


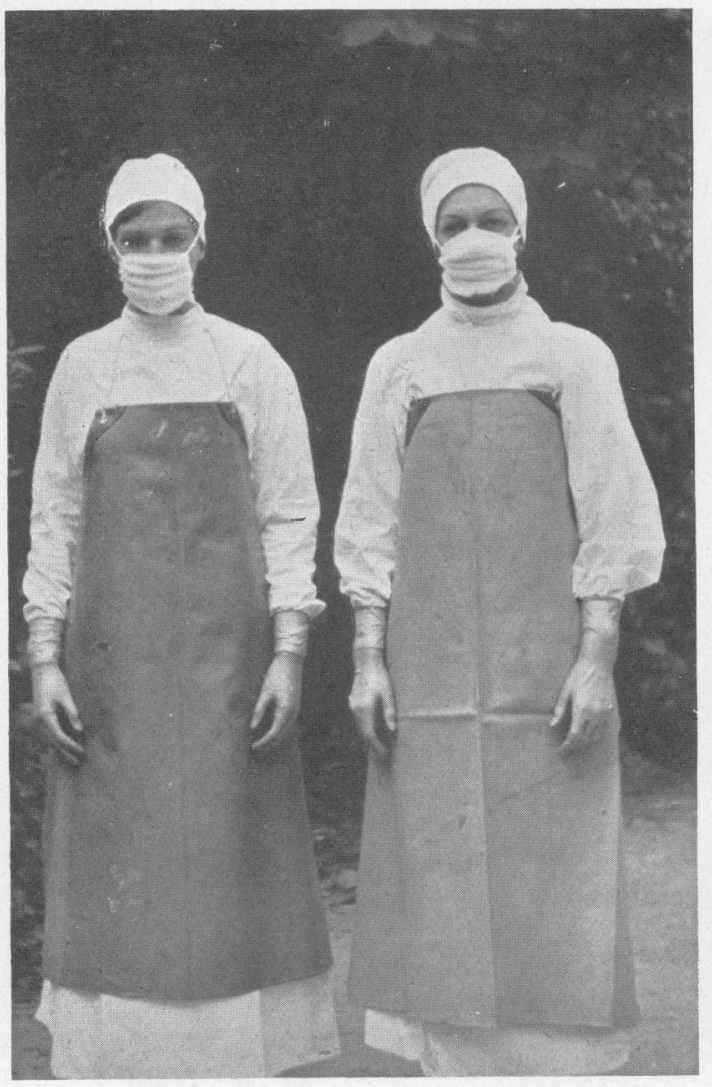

FIG. 5.-Protective clothing worn by operators working with large quantities of dry luminous compound.

storey room. The site was cleared to ground level and left open. A good deal of the paint was salvaged. Two years after this we thoroughly examined the place and in a small area about 10 yards horizontal distance from the original store place of the radium we found indications of not less than $5 \mathrm{mg}$. of radium.

\section{Conclusions}

Measurements indicate that workers in most ordinary luminizing factories are not suffering from excessive exposure either to radon in a contaminated atmosphere or to radium dust.

In some cases the ventilation of dark rooms in these factories could be improved.

Workers with larger quantities of radium, for example in the preparation of luminous compound, are exposed to greater risks, and in these cases we regard the risk of the inhalation of radium dust as particularly important. Moreover, such workers are not protected by any special regulations.

The situation is on the whole reassuring and we consider that, if the Ministry of Labour regulations are rigidly adhered to and the necessary routine tests made, there will be no need to look on this industry as a dangerous occupation.

\section{Summary}

A short account is given of the hazards involved in radium dial painting and of the physical measurements

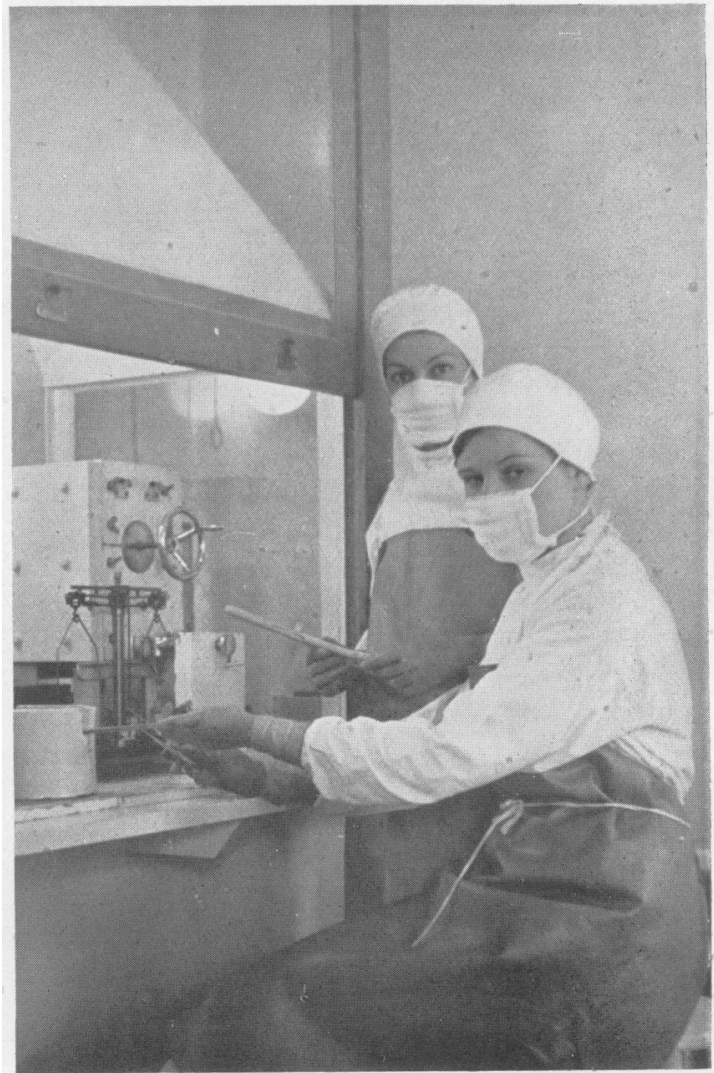

FIG. 6.-Bottle filling at a factory manufacturing luminous compound.

(By courtesy of Brandhurst Company, Reading.)

necessary for their control. The recommended tolerance figures for the quantity of radium in the body and for the concentration of radio-active material in the atmosphere are discussed. Results of measurements made on operatives and workrooms are given.

\section{Acknowledgments}

Most of the work was carried out for the Medical Research Council at the Middlesex Hospital and was under the direction of Professor S. Russ to whom we are greatly indebted. Visits to the factories concerned were arranged by Dr. Ethel Browning of the Factory Department, Ministry of Labour. The gamma-ray tests were made possible by the kindness of Dr. L. H. Gray and the Mount Vernon Hospital, Northwood.

\section{REFERENCES}

British X-ray and Radium Protection Committee Recommendations, Feb. 1943 .

Browning, E. (1944). Brit. J. indust. Med., 1, 170.

Curtiss, L. F. (1942). J industr, Hyg., 24, 131.

Evans, R. D. (1943). Ibid., 25, 253 .

Factories (Luminising) (Health and Safety Provisions) Orders, made by the Minister of Labour under Regn. 60 of the Defence Regulations, 1939. No. 703 (1942); No. 1503 (1943).

Gray, L. N., and Read, J. (1942). Brit. J. Rad., 15, 320. Hemeon, W. C. L., and Evans, R. D. (1942). J. ind

Martland, H. S. (1931). Amer. J. Cancer, 15, 2435.

Morris, G. E., Tabershaw, I. R., Skinner, J. B., and Bowditch, M. (1943). J. industr. Hyg., 25, 270.

Mottram, J. C., and Read, J. (1939). Brit. J. Rad., 12, 54

Read, J. (1939). Ibid., 12, 632.
Williams, C. R., and Evans, R. D. (1942). J. industr. Hyg., 24, 236. 